\title{
Consentimiento en el contrato: causal de nulidad y no de anulabilidad
}

\author{
Consent to the contract: grounds for nullity and not for voidability \\ Consentimento ao contrato: fundamento de nulidade e não de anulabilidade
}

Artículo recibido en mayo 2020

Arbitraje en junio 2020

Aceptación en junio 2020

Publicación en julio 2020

\section{Iván Fernando Vidal Aparicio}

ivanfervidal@gmail.com

https://orcid.org/0000-0002-1700-9875

Universidad San Francisco Xavier de Chuquisaca, Sucre, Bolivia
RESUMEN

ABSTRACT

RESUMO
Este artículo abordó la importancia de la correcta identificación de las causales de nulidad y anulabilidad, con el objetivo de evidenciar que la falta de consentimiento en el contrato es causal de nulidad y no de anulabilidad. Centrándose en el ámbito de materia civil, aplicación de conceptos o categorías jurídicas civiles de la nulidad o nulidad absoluta y anulabilidad o nulidad relativa. Como resultado se identificó que los códigos civiles de México y Perú establecen con claridad su base teórica doctrinaria respecto a la nulidad, a diferencia de los códigos civiles de Bolivia, Francia, Italia, España y Argentina. Se concluyó identificando la necesidad del traslado de la causal de anulabilidad del contrato, "por falta de consentimiento para su formación", establecida en el numeral 1) del art. 554 del Código Civil Boliviano, a las causales de nulidad del contrato enunciadas en el art. 549 del mismo cuerpo legal.

Palabras clave: Contrato; Causa de nulidad; Causa de anulabilidad; Derecho comparado; Derecho civil

This article addresses the importance of correctly identifying the grounds for nullity and voidability, with the aim of showing that the lack of consent in the contract is grounds for nullity and not voidability. Focusing on the field of civil matters, application of civil legal concepts or categories of nullity or absolute nullity and nullity or relative nullity. As a result, it was identified that the civil codes of Mexico and Peru clearly establish their doctrinal theoretical basis regarding nullity, unlike the civil codes of Bolivia, France, Italy, Spain and Argentina. It was concluded by identifying the need to transfer the cause of voidability of the contract, "due to lack of consent for its formation", established in numeral 1) of art. 554 of the Bolivian Civil Code, to the grounds for nullity of the contract set forth in art. 549 of the same legal body.

Key words: Contract; Cause of nullity; Cause of voidability; Comparative law; Civil law

Este artigo aborda a importância de se identificar corretamente os fundamentos da nulidade e da anulabilidade, com o objetivo de mostrar que a falta de consentimento do contrato é motivo de nulidade e não de anulação. Centrando-se no domínio da matéria civil, aplicação dos conceitos jurídicos civis ou das categorias de nulidade ou nulidade absoluta e nulidade ou nulidade relativa. Como resultado, identificou-se que os códigos civis do México e do Peru estabelecem claramente suas bases teóricas doutrinárias sobre a nulidade, ao contrário dos códigos civis da Bolívia, França, Itália, Espanha e Argentina. Concluiu-se identificando a necessidade de transferência da causa de anulabilidade do contrato, "por falta de consentimento para a sua constituição", prevista no ${ }^{\circ}$ 1) do art. 554 do Código Civil Boliviano, ao fundamento de nulidade do contrato previsto no art. 549 do mesmo órgão jurídico.

Palavras-chave: Contrato; Causa de nulidade; Causa da voidability; Lei comparativa; Direito Civil 


\section{INTRODUCCIÓN}

La doctrina clasifica los hechos jurídicos en hechos jurídicos propiamente tales, hechos jurídicos voluntarios y actos jurídicos. Estos últimos son acciones realizadas por el hombre, con intención de producir efectos jurídicos; se extienden al derecho positivo como actos realizados por el hombre con clara conciencia de su efectividad jurídica. Julien Bonnecase, citado por Moscoso (1977) define al acto jurídico en sus esferas pública y privada como "una manifestación exterior de voluntad, unilateral o plurilateral, cuyo objeto es crear, modificar o extinguir una relación o una norma jurídica" (p. 150). Tomado a este acto como la manifestación exterior de la voluntad, sea unilateral o plurilateral. La forma más usual y simple del acto jurídico y con mayor importancia en la teoría y práctica del derecho es la plurilateral.

La misma dependencia que se da entre acto jurídico y convención existe entre convención y contrato. En el artículo 1.101 del Código Civil Italiano se considera al contrato como convención por la que una persona se obliga hacia otra a dar, hacer o no hacer algo (Mazeaud, 1960). Entonces, el contrato es una convención generadora de derecho. La terminología no siempre se respeta rigurosamente, incluso en el Código Civil Boliviano, donde la palabra convención se utiliza con frecuencia como sinónimo de contrato, inclusive a momento de dar una noción de lo que es un contrato, en su art. 450.

En Bolivia, los requisitos de formación de los contratos son enunciados en el artículo 542 del Código Civil, enumerando cuatro requisitos esenciales para la formación de los contratos: consentimiento de las partes, objeto, causa y forma, siempre que sea legalmente exigible o requerida por ley. La sanción de su inobservancia es la nulidad y la anulabilidad del contrato, dependiendo el caso. Corresponde puntualizar que el consentimiento significa permitir algo, aceptar una oferta o proposición, obligarse (Osorio, 1975).

En la contratación, cuando se dan todos los elementos constitutivos para la formación de los contratos establecidos en el Art. 452 del Código Civil (consentimiento, objeto, causa y forma) y los exigidos para cada contrato en particular, así como cuando los contratantes son personas capaces de realizar el negocio, el contrato es perfecto, siendo por tanto válido. Por otro lado, la invalidez de un contrato puede deberse a causales coetáneas a su nacimiento o a causales sobrevinientes. Para el presente trabajo, interesa la primera; y, en esta entran la nulidad, la anulabilidad y la rescindibilidad. Siguiendo la lógica de la presente ponencia, se profundizará sobre la primera y la segunda. El objetivo del estudio fue evidenciar que la falta de consentimiento en el contrato es causal de nulidad y no de anulabilidad.

\section{MÉTODO}

El presente artículo abordó la importancia de consignar como causal de nulidad la falta del consentimiento en la formación de los contratos, entendiendo que esta es la expresión de 
voluntad libre de las partes que contratan, para obligarse legal y válidamente. Centrándose en el estudio de materia civil, libro de las obligaciones, implicancias, conceptualizaciones, aplicación de conceptos o categorías jurídicas civiles de la nulidad o nulidad absoluta y anulabilidad o nulidad relativa.

El análisis se realizó bajo el paradigma sociocrítico, siguiendo la guía de un caso de estudio. Los involucrados en este último han sido mantenidos en el anonimato para preservar los derechos humanos y legales.

El estudio se desarrolló en cinco etapas: primero, se presenta la base teórica que respalda el tema; segundo, se analizan el caso, los fundamentos y el problema; tercero, se presentan las consecuencias; cuarto, se concluye con el aporte de una propuesta de modificación de ley. Finalmente, en el apartado discusión se respalda la propuesta de ley en el derecho comparado, considerando los casos de Francia, Italia, España, Argentina, México y Perú.

RESULTADOS

El abordaje se presenta en cuatro apartados: base teórica referente a nulidad y anulabilidad; análisis y fundamentos del problema; consecuencias y propuesta de ley.

\section{Nulidad y anulabilidad}

Las nulidades son:

sanciones [...] a contratos que no contienen requisitos esenciales de formación [...] donde el consentimiento está viciado o provienen de contratantes incapaces, o cuyo objeto [...] carece de elementos esenciales y la causa es lícita, así como a los que transgreden normas jurídicas imperativas (Kaune, 2005, p. 271).

La nulidad se constituye en una forma de ineficacia que deriva de un vicio sustancial de legalidad en cualquiera de los presupuestos del acto o negocio jurídico en el momento de su celebración. Evidentemente, la nulidad del acto jurídico reside en un vicio originario y sustancial de legalidad, con ineficacia ex tunc, que impide que un acto irregular defectuosamente celebrado pueda surtir efectos.

La teoría tripartita de nulidad comprende actos inexistentes, actos nulos y actos anulables. La teoría bipartita comprende sólo actos nulos y actos anulables. Existen otras teorías que sostienen que la nulidad puede ser absoluta y relativa; o nulidad manifiesta y no manifiesta; o nulidad completa, radical o total y parcial. La doctrina italiana distingue entre actos inexistentes y nulos (carece de utilidad práctica porque los efectos de nulidad e inexistencia son los mismos).

Caracteres de nulidad: imprescriptibilidad, no sólo como acción sino como excepción (art. 552 C.C.); inconfirmabilidad, no admite la confirmación (art. 553 C.C.) y; es de orden público, porque se da en defensa de la sociedad y puede ser denunciada por cualquier persona que tenga interés (art. 551 C.C.). 
Caracteres de anulabilidad: prescribe como acción a los cinco años, pero no así la excepción que es imprescriptible y puede oponerse en cualquier momento (art. 556 C.C.); es susceptible de ser subsanada mediante la confirmación por parte del sujeto a quien la ley protege con la acción de la anulabilidad (art. 558 C.C.); se da en defensa de las personas expresamente señaladas por la ley, de ahí que solo éstas o sus representantes legales pueden hacer uso (art.555 C.C).

Ambas, nulidad y anulabilidad, constituyen sanciones que son previstas por ley e impuestas por el juez; tienen efectos con carácter retroactivo. El Art. 549 del C.C. en sus cuatro primeros incisos se refiere a las nulidades textuales al disponer que el contrato es nulo por: falta de objeto o forma prevista por ley como requisito de validez; faltar en el objeto del contrato; ilicitud de la causa o motivo que impulsó a las partes a celebrar el contrato; error esencial que recae sobre la naturaleza o sobre el objeto del contrato; demás casos determinados por la ley. Las nulidades virtuales dan lugar al principio de la especificidad que surge de las previsiones contenidas en los Arts. 90 caso primero y 351 del Código de Procedimiento Civil. El numeral 5) del Art. 549 del Código Civil, se refiere a estas nulidades que son las transgresiones a las disposiciones contenidas en normas imperativas.

Por otra parte, las causas de anulabilidad se encuentran especificadas en el Art. 554 del Código Civil. El contrato será anulable: por falta de consentimiento para su formación; por incapacidad de una de las partes contratantes; porque una de las partes, sin haber sido declarada interdicta y siempre que resulte mala fe en la otra parte, no haya estado en condiciones de entender o aceptar el tenor del contrato; por violencia, dolo, error sustancial sobre la materia o sobre las cualidades de la cosa; por error sustancial sobre la identidad o las cualidades de la persona cuando ellas hayan sido la razón o motivo principal para la celebración del contrato; en otros casos determinados por ley.

\section{Análisis y fundamentos del problema}

El caso de estudio considera la jurisprudencia sentada al respecto en el Auto Supremo No. 124, de Sala Civil, dictada en Sucre - Bolivia el 2002 (Poder Judicial de Bolivia, 2002) al fallar sobre la pretensión de una falta de consentimiento por falta de firma en un contrato, demandada como nulidad y no como anulabilidad, es decir, el juez a quo, desestimó la demanda por no comprender el art. 549 del Código Civil, la causal de falta de consentimiento. Pero, el juez ad quen no lo creyó así, y finalmente se casa el auto de este último, sin dar razón y confirmando la sentencia del juez a quo.

La Corte Suprema de Justicia de Bolivia (2008, art. 2-3), en su Considerando segundo dice:

...si la demanda así se halla interpuesta significa que en el documento de compraventa falta uno de los requisitos para la formación del contrato como es el consentimiento, previsto por el art. 452-1) del Código Civil. Si ello es así, la demanda de manera alguna podría ser por la nulidad del referido documento 
por si se alega falta de consentimiento (falta de firma) se inscribe entre las causales de anulabilidad del contrato, prevista en el art. 554-1) del Sustantivo Civil y de ninguna manera en las causales previstas por el art. 549 del Código Civil de nulidad [...] Por las conclusiones anteriores se infiere que la demanda versa por la "nulidad" del contrato de transferencia y no sobre "anulabilidad", situación que es muy importante aclarar no solo para la valoración de las pruebas aportadas por las partes litigantes sino para la decisión de la causa [...] por lo que corresponde la aplicación de los arts. 271-4) y 274 del Adjetivo Civil.

\section{Análisis procesal}

Las normas de invalidez, nulidad y anulabilidad, salvaguardan las leyes de la erosión de las acciones contrarias y requieren acto de autoridad. La cuestión es si la previsión normativa de invalidez de actos evita realmente su realización o si cumple una función disuasoria. En el último caso se asimilaría la invalidez a la sanción.

\section{Demanda, contestación, sentencia y congruencia}

El abogado patrocinante, una vez identificada la invalidez del contrato, entrará en la disyuntiva al plantear la demanda conforme a derecho, es decir, plantearla como nulidad o anulabilidad. No existe mucha dificultad cuando se trata de una invalidez que entra dentro de los requisitos exigidos por la norma para interponer una demanda por anulabilidad, es decir que el demandante sea una de las partes intervinientes en el contrato inválido y que esté dentro del plazo establecido para la prescripción de la acción civil (arts. 555 y siguientes del Código Civil). La acción como derecho subjetivo autónomo, como facultad de acudir a los órganos jurisdiccionales, en el caso se desvía, ya que la falta de consentimiento no está debidamente protegida como una acción de carácter público de protección a la sociedad, sino simplemente está establecida como una acción privada, a la cual acceden ciertas personas.

No es posible demandar a la vez nulidad y anulabilidad, peor aún, esperando que venga una sentencia al azar, mezclando desde un inicio todas las causales y los hechos que fundamentan la pretensión, sin tomar en cuenta los efectos de cada una de ellas, sustentan esta posición la doctrina y jurisprudencia, al indicar que son dos acciones antitéticas.

Esta demanda puede ser utilizada por la parte demandada favorablemente, siendo el caso de aplicación de la prescripción de la acción de anulabilidad, inclusive negando una confirmación del contrato que adolece de invalidez por falta de consentimiento en forma previa, obligando a su contraparte a acudir a una acción civil por anulabilidad y no por nulidad con todos sus requisitos y efectos favorables en su propio caso. El debido proceso no se encuentra ante esta problemática protegido, se ha iniciado una marcha buscando una sentencia que tal vez no sea tan justa. 
Concluido el periodo de prueba, el juez repasará los hechos y su calificación jurídica según las normas de nulidad o anulabilidad que es el caso, realizando detalles relevantes de los elementos conducentes, hechos, norma, calificación jurídica para llegar a un fallo o resolución definitiva. Como juzgar sabiendo que la causal de falta de consentimiento está sometida erróneamente a los requisitos de la anulabilidad y no de la nulidad, sabiendo que en el caso de la anulabilidad se obtendrá una sentencia constitutiva.

El deber del Juez o Tribunal es ser congruente en sus sentencias o resoluciones de fondo, de carácter civil con las pretensiones deducidas por las partes litigantes, siendo reflejo y proyección del haz de consecuencias directas que conlleva el principio dispositivo y así lo ha venido manteniendo la doctrina. Sea esta incongruencia ultra petita en la que se incurre si el Tribunal concede en la resolución más de lo pedido o resistido por las partes, o excesiva; extra petita para los supuestos en que el juzgador concede algo distinto o fuera de lo solicitado por las partes; citra petita, si bien algún sector lo conceptúa como infracción, omisión en la que se incurre cuando el Tribunal no se pronuncia sobre alguno de los pedimentos que le han sido planteados. Si la falta de consentimiento es demandada conforme el art. 554 numeral 1) del Código Civil, se corre el riesgo de ser incongruentes, pues lo pedido puede estar errado, por lo menos doctrinalmente; evidentemente el apego a la norma escrita provee congruencia, permite resolver la falta de consentimiento conforme la anulabilidad y no la nulidad.

¿Es posible aplicar la interpretación de las normas?

La interpretación comienza en el legislador y termina en el funcionario que practica el acto procesal de ejecución y coacción e inclusive con coerción. En consecuencia, el intérprete original o primigenio, en el caso es el legislador y es quien dará una razón y consecuencia de lo que implica la nulidad, según el numeral 1) del art. 554 del Código Civil.

En el caso estudiado no existe posibilidad de doble interpretación, pues no se encuentra en otro articulado (sea del mismo Código Civil u otro código) una norma que sea igual o parecida en significancia en todo o en parte al numeral 1 ) del art. 554, es único y hasta determinante. El sentido real de la norma jurídica no puede ser identificado generalmente con el pensamiento que tuvo el legislador al instituirla o crearla, esto por la insuperable limitación del humano.

Dejando atrás el punto de vista del legislador, el único sentido de la norma que puede ser considerado como auténtico es el que tiene por sí misma, aquel que la sostiene desde su propio sentido y fondo, el que viene a ser su propio espíritu peculiar e intransferible. La discusión actual y sobre el numeral 1) del art. 554 del Código Civil, no se centra en su existencia o no, en su validez o no, en su buena redacción o no, en su explícita alusión al consentimiento o no, o en su correcta implicancia dentro la teoría del consentimiento; sino en su correcta ubicación. Las normas deben ser dinámicas, afirmando su actualidad en progresión y ajustándose con las nuevas realidades a los sucesos posteriores a su establecimiento, y las relaciones sociales 
posteriores a su establecimiento también deben estar contempladas en ellas. Es decir, si existe error en su ubicación doctrinal y legal, esto se debe corregir con nuevas ponencias doctrinales y legales.

Podría utilizarse métodos para captar el sentido fidedigno de la norma, que permitan desentrañar su sentido propio para interpretar el numeral 1) del art. 554 del Código Civil.

Si los mismos no ayudan a darle un sentido o posicionamiento correcto; el gramatical puede captar el significado de las palabras. En el caso, gramaticalmente hablando el numeral 1) del art. 554 del Código Civil es indubitablemente ese, la falta de consentimiento, como causal de anulabilidad y no de nulidad.

¿Es posible aplicar la integración del derecho?

En el caso de estudio la integración del derecho no es aplicable por no constituir la falta de consentimiento una norma que no está plasmada en el Código Civil en forma no clara y ambigua, sino que está mal ubicada.

Sin embargo, es necesario resaltar que en otros casos el legislador puede abrogar las leyes y formular una nueva legislación opuesta a la anterior, o establecer excepciones dentro la legislación vigente, el juez no puede fallar en contradicción con la legislación vigente, porque si hay una norma que concierne a la cuestión en litigio, de acuerdo con su correcta interpretación, obligadamente tendrá que aplicarla. La consistencia armónica del sistema jurídico repudia la existencia de normas opuestas entre sí, el juez al suplir una laguna jurídica aplicará los principios generales del derecho, equidad y analogía, que no estén obviamente en discordia con los preceptos positivos o vigentes.

¿Existe forma o recurso legal que permita resolver el problema?

No existen recursos ordinarios o extraordinarios en materia civil que permitan dilucidar y resolver el problema; entonces ¿existen recursos constitucionales que lleven a ello? En Bolivia, existen controles de constitucionalidad en dos vías, el difuso y el concentrado, en sí, es una mezcla o sistema combinado. En el caso sería indicado aplicar el control difuso (desde la óptica de la interposición de un recurso constitucional, según el numeral 1) del art. 554 del Código Civil.

El art. 7 de la Ley del Tribunal Constitucional, concordante con el art. 202 de la Nueva Constitución Política del Estado, dispone varias atribuciones del Tribunal Constitucional, de todas estas posibilidades; sólo tres podrían indicar algún camino de solución al problema (en el contexto del numeral 1) del art. antes citado. 
El numeral 2) del artículo estudiado refiere a recursos indirectos o incidentales de inconstitucionalidad contra leyes, pero promovidos dentro un proceso judicial, condicionados a la existencia de una duda razonable y fundada sobre la constitucionalidad de una ley (tal vez el numeral 1 del art. 554 del Código Civil), decreto o resolución no judicial y la existencia de una sentencia o resolución final pendiente a la que sea aplicable la ley.

También se puede recurrir a un recurso de amparo constitucional, demandando sumarísimamente actos ilegales u omisiones indebidas de los funcionarios o particulares que restrinjan, supriman o amenacen restringir o suprimir los derechos y garantías de las personas reconocidas por la constitución y las leyes, siempre que no haya otro recurso inmediato para la protección de los derechos y garantías lesionados.

En el caso y problema de estudio, con referencia a las tres posibilidades antes referidas, no existe el requisito primordial para la interposición de un recurso constitucional porque el problema es eminentemente civil o de derecho civil.

¿Puede la jurisprudencia ordinaria o constitucional solucionar el problema?

La jurisprudencia tiene un ciclo vital con tres fases o etapas: nacimiento, desarrollo y muerte. Lo importante es estudiar su etapa de vigencia como derecho vivo. En este contexto la pregunta es cuán viva está la jurisprudencia. Repetir de manera dogmática, que hay un arreglo preestablecido de fuentes de manera natural y eterna, para solucionar el problema, sabiendo que la teoría que señala estas fuentes del derecho en servicio de solucionar otros problemas, acarrea preguntas como ¿que fuentes del derecho se tiene a disposición?, ¿qué ventajas y desventajas tiene la creación del derecho a través de estas fuentes?, ¿qué problemas sociales o jurídicos pueden ser resueltos a través de determinadas fuentes?, y ¿pueden las fuentes del derecho resolver el problema estudiado? Se tendría que hacer una reingeniería de fuentes, para establecer de manera dogmática y legislativa el alcance de esas fuentes.

Pero, todo este poder como fuente del derecho de la jurisprudencia, sea constitucional o civil, no alcanza para solucionar el problema del caso de estudio, sobre la falta de consentimiento como causal de anulabilidad y no de nulidad. Con lo dicho, no es posible buscar amparo en la jurisprudencia constitucional, porque no ofrece temas relevantes en materia civil, no habiéndose avanzado en la temática de las nulidades y anulabilidades civiles.

¿Pueden la doctrina o la costumbre solucionar el problema?

Siendo la doctrina la opinión autorizada emitida por juristas sobre un tema controvertido de derecho (Couture, 1978). Es posible que la doctrina en materia civil sea autorizada, racional y emitida por connotados juristas; pero, deberá ser pesada conjuntamente a la legislación y la jurisprudencia contra la ley. 
No existe costumbre contra la ley, es decir, no es correcto intentar mediante la costumbre dejar de lado la imposición de la falta del consentimiento como causal de anulabilidad, inserto dentro del art. 554 numeral 1) del Código Civil. Deduciendo que, la doctrina y la costumbre, son evidentemente dos fuentes importantes del derecho, pero, no soslayan lo establecido en el numeral 1) del art. 554 del Código Civil Boliviano.

\section{Consecuencias}

No se ha encontrado solución al problema, ni en la doctrina ni en la práctica procesal del derecho. Se analizan las consecuencias.

Tiempo y recursos económicos: a la sociedad le interesa terminar rápido y con éxito sus pleitos legales, sin perder tiempo ni dinero, pero el problema estudiado, procesalmente se lo impide, por las causas y efectos analizados. Al interponer una demanda incorrectamente, como se encuentra establecida la falta de consentimiento, esta se perderá si es que era necesario utilizarla conforme a las reglas de la nulidad. Evidentemente, por sus efectos de protección y públicos son mucho más favorables tomando en cuenta además que hasta el error esencial sobre la naturaleza o sobre el objeto del contrato se encuentra protegido por la nulidad (art. 549 numeral 4 del Código Civil).

Las diferencias entre nulidad y anulabilidad impiden someter un mismo rigor procesal. Son notorias estas diferencias procesalmente hablando. Si la falta de consentimiento fuera demandada como casual de anulabilidad, tendría la desventaja de someterse por intermedio sólo de una persona en cuyo interés y protección haya sido establecida, acción que no esté prescrita ( 5 años) y en base a una obligación que no haya sido confirmada (arts. 555, 556 y 558 del Código Civil).

Al haber definido como jurisprudencia la Corte Suprema de Justicia de Bolivia, no puede presentarse como una sola pretensión hechos o contratos con causal de nulidad y anulabilidad, o peticionarse ambas por ser contradictorias, se ha abierto o consolidado una imposibilidad legal de demandar ambas. Del mismo modo, no puede demandarse la falta de consentimiento como nulidad y, por ende, esta causal se ha consolidado como letra muerta de la ley y del art. 554 en su numeral 1) del Código Civil, causando que, a pesar de ser probadas en sentencia y confirmadas en autos de vista superiores, hayan sido anuladas o no casadas en autos de vistas supremos.

La ambigüedad del sistema de justicia en Bolivia, los jueces no deberían dar razón total y en letra muerta a las normas plasmadas literalmente en los códigos escritos. Ésta es una difícil tarea. 


\section{Proyecto de Ley}

Se expone una propuesta de proyecto de Ley que hará posible la modificación de los arts. 549 y 554 del Código Civil.

\section{DE LA NULIDAD DEL CONTRATO}

Artículo 1.- (Casos de nulidad del contrato)

Modificase el Art. 549, en los siguientes términos:

Art. 549.- (Casos de nulidad del contrato).

El contrato será nulo:

1) Por falta de consentimiento para su formación.

2) Por faltar en el contrato, el objeto o la forma prevista por la Ley como requisito de validez.

3) Por faltar en el objeto del contrato de los requisitos señalados por la Ley.

4) Por ilicitud de la causa y por ilicitud del motivo que impulsó a las partes a celebrar el contrato.

5) Por error esencial sobre la naturaleza o sobre el objeto del contrato.

6) En los demás casos determinados por la Ley.

\section{DE LA ANULABILIDAD DEL CONTRATO}

ARTíCULO 2.- (Casos de anulabilidad del contrato)

Modificase el Art. 554, en los siguientes términos:

Art. 554.- (Casos de anulabilidad del contrato)

El contrato será anulable:

1) Por incapacidad de una de las partes contratantes. En este caso la persona capaz no podrá reclamar la incapacidad del prohibido con quien ha contratado.

2) Porque una de las partes, aún sin haber sido declarada interdicta, era incapaz de querer o entender en el momento de celebrarse el contrato, siempre que resulte mala fe en la otra parte, apreciada por el perjuicio que se ocasione a la primera, según la naturaleza del acto o por otra circunstancia.

3) Por violencia, dolo o error sustancial sobre la materia o sobre las cualidades de la cosa.

4) Por error sustancial sobre la identidad o las cualidades de la persona cuando ellas hayan sido la razón o motivo principal para la celebración del contrato.

5) En los demás casos determinados por la Ley. 


\section{DISPOSICIONES FINALES}

\section{ÚNICA. (Vigencia y Derogaciones)}

I. La presente Ley entrará en vigor en la fecha de su publicación.

II. Se derogan todas las disposiciones contrarias a lo dispuesto en la presente Ley.

DISCUSIÓN

Se analiza la falta del consentimiento como causal de nulidad en el derecho comparado.

\section{Francia}

Su origen se remonta a 21 de marzo de 1804, fue la base del llamado Código Civil Santa Cruz. El art. 1108 de este código menciona como requisitos esenciales de validez de los contratos (Santos, 2005); su capacidad de contratar; un objeto cierto que forme la materia del compromiso y a una causa lícita en la obligación. Agrega el art. 1109 que no habrá consentimiento válido si éste hubiera sido dado por error, o si hubiera sido arrancado con violencia u obtenido mediante dolo; el error (art. 1110) sólo será causa de nulidad del contrato cuando recaiga sobre la sustancia misma de la cosa que constituya su objeto, como en el boliviano (art. 549 numeral 4 del Código Civil). La violencia y el dolo son causales de nulidad y no existe un listado de causales de nulidad o anulabilidad.

Italia

Es notable la igualdad del artículo 1325 del Código Civil Italiano (Código Civil de Italia, 2008), con el art. 452 del Código Civil Boliviano, cuando se trata de los requisitos de validez de los contratos, una muestra que avala que el Código Civil Boliviano vigente desde el año 1976 tiene, en parte, base Italiana; continuando, el art. 1325 señala como requisitos del contrato el acuerdo de partes (1326 y siguientes,1427), la causa (1343 y siguientes), el objeto (1346 y siguientes) y la forma, cuando resulte de la prescripción de la ley (1350 y siguientes); último, que señala la forma no establecida en los Códigos Civiles Francés ni Español, pero si establecidos en algunos Códigos Civiles Latinoamericanos.

El art. 1418 cita las causales de nulidad, señalando que el contrato es nulo cuando es contrario a la norma imperativa, salvo que la ley disponga otra cosa, al parecer incluiría a la falta del consentimiento; siendo también nulo el contrato (art. 1419 del Código Civil Italiano, sobre la nulidad parcial del contrato) si resulta que alguna de sus cláusulas o una parte de contrato fue motivo determinante del contrato completo (idéntico por demás al art. 550 del Código Civil Boliviano), además de que ésta (cláusula) no sea sustituto de alguna norma imperativa. La violencia, dolo y error son causales de anulabilidad (arts. 1425 al 1427). 
El Código Civil Italiano tiene articulados parecidos al Código Civil Boliviano, pero tampoco tiene un listado de causales de nulidad. En el contexto italiano ven que los efectos de ambos (nulidad y anulabilidad) sean lo menos gravoso, como ejemplo de la legitimación y conversión que se produce cuando no se la hizo valer por el interesado a quien le favorece (arts. 1421 y 1424).

\section{España}

El régimen jurídico de la nulidad de los contratos en el derecho español está en el Código Civil de 1884 (régimen general, arts. 1300-1314), modificado por la Ley de Enjuiciamiento Civil, y en otras normas dispersas (Leyes especiales). En España (Código Civil de España, 2008), a diferencia de la nulidad absoluta, la anulabilidad no puede apreciarse de oficio por el Juez. La acción de nulidad es el cauce procesal por el que se hace valer la invalidez contractual, tanto para la nulidad absoluta, como para la nulidad relativa. El Juez puede aplicar de oficio lo dispuesto en el artículo 1303 del Código Civil Español, ya que de la nulidad se deriva la correspondiente obligación de restitución. El art. 1.303, en una consideración puramente doctrinal, se encuentra situado en un conjunto de reglas que parecen referirse a lo que más técnicamente se denomina hoy anulabilidad.

El art. 1258, habla sobre la importancia del consentimiento, que al igual que en la legislación boliviana, el contrato se perfecciona con el simple consentimiento de las partes, el consentimiento como requisito de validez de los contratos es tratado a partir del art. 1262. Al igual que el Código Civil de Francia no tiene como requisito de validez de los contratos a la forma. Asimismo, se usa el vocablo "nulo" (igual que el francés) en el art. 1265, cuando se trata de vicios del consentimiento como ser el error, violencia, intimidación o dolo. El art. 1300 del Código Civil Español, refiere que los contratos en que concurran los requisitos que expresa el artículo 1.261 pueden ser "anulados", aunque no haya lesión para los contratantes, siempre que adolezcan de alguno de los vicios que los invalidan con arreglo a la ley.

En sentido literal lo mencionado respecto a la nulidad y anulabilidad en España, es contradictorio doctrinalmente e utilizados indistintamente, ya que los vicios del consentimiento se encuentran dentro las causales de nulidad y son anulables los actos que van en contra de los requisitos de validez de un contrato. Pero el art. 1301, de que la acción de nulidad sólo dura 4 años (la teoría civil dice que los contratos nulos no tienen tiempo de prescripción\}. Entendiéndose de una lectura completa y sistemática del Código Civil Español que tiende a unificar los vocablos nulidad y anulabilidad, situación percibida por su jurisprudencia.

De la misma forma que en los Códigos Civiles de Italia y Francia, el de España no menciona o encasilla explícitamente a la falta del consentimiento, pero, hace una valiosa referencia al mencionar que cualesquier soslayo a los requisitos de validez del contrato es anulable (entre ellos el consentimiento). 


\section{Argentina}

El Código Civil de Argentina (2008), no tiene un articulado que manifieste los requisitos de validez de los contratos, su art. 502 refiere que la obligación fundada en una causa ilícita, es de ningún efecto, en concordancia con los arts. 900 y 913, que indican que los hechos que fueren ejecutados sin discernimiento, intención y libertad, no producen por sí obligación alguna y que ningún hecho tendrá el carácter de voluntario sin un hecho exterior por el cual la voluntad se manifieste.

En muchos de sus artículos utiliza indistintamente los vocablos nulidad y anulabilidad, como se verifica en el art. 1046 indicando que los actos anulables se reputan válidos mientras no sean anulados; y sólo se tendrán por nulos desde el día de la sentencia que los anulase; los arts. 924, 925, 926 y 927, versan sobre el error indicando que producen anulabilidad cuando se trata de la naturaleza del acto jurídico, error esencial en la persona, error en las cualidades de la cosa, (similar al Código Civil Boliviano). El art. 927 indica que hay anulabilidad por error en el objeto, que en Bolivia es causal de nulidad. Es anulable también todo acto jurídico que implique dolo violencia, intimidación o simulación como versa el art. 954, igual que en Bolivia. Se acepta la división bipartita de las nulidades expresada en el art. 1039. A partir del art. 1041 al 1044 refiere a la nulidad, por incapacidad absoluta o relativa (diferente) y por simulación o fraude de los actos jurídicos (no comprendido por el Código Civil Boliviano). Existe la posibilidad de confirmación de los actos nulos y anulables enunciados en los arts. 158 y siguientes (diferente a los arts. 553 y 558 del Código Civil Boliviano).

\section{México}

La legislación Mexicana Federal (Código Civil de México, 2002), adopta la teoría tripartita de las nulidades, y establece que el acto jurídico es inexistente por la falta de consentimiento o de objeto, según su art. 2.224. Señala que la ilicitud en el objeto, en el fin o en la condición del acto produce su nulidad ya sea absoluta o relativa. La falta de forma establecida por la ley, si no se trata de actos solemnes, así como el error, el dolo, la violencia, la lesión y la incapacidad de cualquiera de los autores del acto, produce la nulidad relativa del mismo.

Este Código Civil instituye con absoluta claridad su base teórica doctrinaria respecto a la nulidad, aspecto que respalda que la falta de consentimiento como causal de invalidez de los contratos debe estar comprendida dentro las causales de nulidad y no de anulabilidad. El mismo comentario merece el Código Civil del Perú.

\section{Perú}

El Código Civil del Perú (Civil, 1984), establece que son nulos los siguientes actos jurídicos: cuando falta la manifestación de voluntad del agente; cuando se haya practicado por persona absolutamente incapaz; cuando su objeto es física o jurídicamente imposible o cuando sea indeterminable; cuando su fin sea ilícito; cuando adolezca de simulación absoluta; cuando no 
revista la forma prescrita bajo sanción de nulidad; cuando la ley lo declara nulo; en el caso del artículo V del Título Preliminar, salvo que la ley establezca sanción diversa. Pero, extrañamente en el art. 140, no se introduce el consentimiento dentro los requisitos de validez de los contratos, si consta la capacidad.

\section{CONCLUSIONES}

La ley es la principal fuente de derecho. Contempla el contrato civil, en todas sus posibilidades, inclusive la posibilidad de la no observancia de sus requisitos de validez y formación. Este hecho implica la nulidad o anulabilidad como sanción, significando que es imposible desmarcarse de la ley para su declaración en la vía judicial. La acción de nulidad se tergiversa, generalmente la falta de consentimiento. No está debidamente protegida como una acción de carácter público, de protección a la sociedad, sino simplemente está establecida como una acción plenamente privada (anulable), a la cual acceden definidas personas.

La interpretación del derecho se torna restrictiva, inclusive reduce el alcance de la falta de consentimiento para la formación del contrato, resultado en una insensible aplicación de su letra muerta, convirtiéndose al final en una injusticia.

La jurisprudencia tampoco solucionará el problema, sea emanada de Tribunales Ordinarios o Constitucional, pues no existe el requisito primordial para la interposición de un recurso constitucional: la pertinencia, valoración, implicancia, canon o mérito constitucional. El problema es eminentemente civil, porque el análisis debe hacerse desde el derecho ordinario y no de la Constitución Política del Estado.

La doctrina es autorizada y racional. En Bolivia es emitida por connotados y destacados juristas. En términos de cuestiones de derecho, como la nulidad y anulabilidad, puede ser que dichos autores tengan razón para argumentar que la causal de falta de consentimiento deba estar dentro de las causales de nulidad y no dentro las causas de anulabilidad; pero, por más acertada y meritoria que sea esta postura, jamás logrará dejar de lado a lo establecido en el numeral 1) del art. 554 del Código Civil.

Las consecuencias de este problema para la sociedad implican tiempo y recursos que gastan los litigantes, ya que las diferencias entre nulidad y anulabilidad impiden someterlas a un mismo rigor procesal; no pudiendo ciertamente demandarse la falta de consentimiento como causal de nulidad; haciendo más pesado el sistema la falta de coherencia de los tribunales de justicia: se admite en algunos casos y rechaza en otros.

Los códigos civiles francés, italiano, español y argentino, que constituyen fuentes de basamento doctrinal del boliviano, no contienen un catálogo de causales de nulidad y anulabilidad como el Código Civil de Bolivia (arts. 549 y 554). Como consecuencia se consigna específicamente la causal de falta de consentimiento, pero no como causal de anulabilidad, sino, como causal de nulidad. 
Finalmente, esincorrecto demandarmedianteuna accióncivillacausal de falta deconsentimiento por la vía de anulabilidad. Lo correcto doctrinal y procesalmente proceder mediante la vía de la nulidad, tomando en cuenta los requisitos de su procedencia y los efectos. Siendo necesario el traslado de la causal de anulabilidad del contrato "por falta de consentimiento para su formación", según establece el numeral 1) del art. 554 del Código Civil Boliviano a las causales de nulidad del contrato enunciadas en el art. 549 del mismo cuerpo legal. Lográndose una mejor compresión de la dimensión teórica y doctrinal del consentimiento y su importancia en materia procesal civil.

\section{REFERENCIAS}

Civil, C. (1984). Código Civil Peruano. Lima, Perú

Código Civil de España. (2008). http://civil.udg. edu/normacivl/estatal/CC/

Código Civil De Italia. (2008). http://www.jus.unint. it/cardozo/obiter_Dictum/cociu/home. html

Código Civil de México, C. C. D. E. (2002). Código Civil del Estado de México

Código Civil del Argentina. (2008). http://www. redetel.gov.ar/Normativa/Archivos $\% 20$ de $\% 20$

Corte Suprema de Justicia de Bolivia. (2008). "Jurisprudencia - Causas". http://jurs. poderjudicial.gov.bo.vi/-l/gj

Couture, E. (1978). "Fundamentos del Derechos Procesal Civil". Editorial Depalma. Buenos Aires - Argentina
Kaune, W. (2005). "Curso de Derecho Civil: Contratos". Alexander. Cochabamba - Bolivia

Mazeaud, H.; MAZEAUD L. \& MAZEAUD, J. (1960). "Lecciones de Derecho Civil". Jurídicas Europa América. Buenos Aires - Argentina. 1960

Moscoso, J. (1977). "Introducción al Derecho". Juventud. La Paz - Bolivia

Ossorio, M. (1995). "Diccionario de Ciencias Jurídicas, Políticas y Sociales". Heliasta. Buenos Aires - Argentina

Poder Judicial de Bolivia. (2002). "Resúmenes de Jurisprudencia 2001". Sucre - Bolivia

Santos, F. J. A. (2005). Código civil francés. Ediciones Jurídicas y Sociales 